\title{
A Comparison between Austroads Pavement Structural Design and AASHTO Design in Flexible Pavement
}

\author{
Behzad Ghadimi ${ }^{1, a}$, Hamid Nikraz ${ }^{2, b}$, Colin Leek ${ }^{3, c}$ and Ainalem Nega ${ }^{4, d}$
}

\begin{abstract}
${ }^{1}$ PhD Candidate, Department of Civil Engineering, Curtin University, GPO Box U1987, Perth, WA 6845, Australia; Tel: (+61) 8 9266-2674; Fax: (+61) 8 9266-2681; Email: Behzad.Ghadimi@ postgrad.curtin.edu.au

${ }^{2}$ Professor, Head of Department of Civil Engineering, Curtin University, GPO Box U1987, Perth, WA 6845, Australia; Tel: (+61) 8 9266-7573; Fax: (+61) 8 9266-2681; Email: H.Nikraz@ @urtin.edu.au

${ }^{3}$ Adjunct Professor, Department of Civil Engineering, Curtin University, GPO Box U1987, Perth, WA 6845, Australia; Tel: (+61) 8 9266-4761; Fax: (+61) 8 9266-2681; Email: C.Leek@ curtin.edu.au

${ }^{4}$ PhD Candidate, Department of Civil Engineering, Curtin University, GPO Box U1987, Perth, WA 6845, Australia; Tel: (+61) 8 9266-2674; Fax: (+61) 8 9266-2681; Email: Ainalem.Nega@ curtin.edu.au
\end{abstract}

a'Behzad.Ghadimi@postgrad.curtin.edu.au, ${ }^{\mathrm{b}} \mathrm{H}$. Nikraz@curtin.edu.au, ${ }^{\mathrm{c}} \mathrm{C}$. Leek@curtin.edu.au dAinalem.Nega@curtin.edu.au

Keywords: AASHTO, Austroads, CIRCLY, KENLAYER, Flexible Pavement.

\begin{abstract}
This study deals with the Austroads (2008) Guide to Pavement Technology Part 2: Pavement Structural Design on which most road pavement designs in Australia are based. Flexible pavement designs and performance predictions for pavements containing one of more bound layers derived from the mechanistic Austroads pavement design methodology and the AASHTO-2004 approach are compared for Australian conditions, with consideration of subgrade and other material properties and local design preferences. The comparison has been made through two well-known programs namely CIRCLY (5.0) and KENLAYER. The study shows that each guide has its own advantages and disadvantages in predicting stress and strain in pavement layers under different conditions. The study recommends that modifications are necessary resulting in more realistic and longer lasting pavements in Australia.
\end{abstract}

\section{Introduction}

Design and maintenance procedures for transportation infrastructures such as road pavements, railway track platforms, and airfield pavements are aimed at assessing the permanent deformations and/or fatigue cracking of the bound or unbound layers. In pavements, permanent deformations of the unbound layers and fatigue cracking of bound layers represent the main cause of distress. Most present pavement design methods used in pavement mechanics are based on so-called mechanistic empirical pavement analysis. Such approaches require calculation of the response of the pavement using a mechanical model to predict the behavior of pavement materials, and then comparing the calculated stresses or strains with empirical design criteria. Two criteria are used, a fatigue criterion for the bound layer based on the maximum tensile strain at the bottom of the layer, and a rutting criterion for the subgrade soil, which consists in limiting the vertical elastic strains at the top of the subgrade.

This study is to review mechanistic empirical approach and then compare two very well-known codes to design pavement layers([1],[2]). The focus of comparison is on the conceptual assumptions inherent in each code on the behavior of pavement materials. Based on those assumptions, one example road has been modeled by CIRCLY and KENLAYER. The results of the study indicate the Australian method results in conservative and more costly pavements. 


\section{Background}

The continued development of Mechanistic-Empirical design process has been the focus of many pavement researchers and based on experimental formulation. However, increasing demand for sustainability in road construction necessitates a fundamental design process which has a capacity to analyze and predict the pavement response accurately.

The basis of Mechanistic-Empirical (ME) pavement design has been recently reconsidered for pavement design. In this method, mechanistic and empirical models are combined to form fundamental of design process. In one hand mechanistic models are to estimate the response of the pavement system in terms of displacement, strains, stresses. On the other hand empirical models associate those responses to observed pavement performance. The objective is to reduce the cost and increase the life-cycle of a pavement.

There are two stages in ME approach; firstly the pavement system is analyzed by one of the mechanistic theories such as elasticity, plasticity and viscosity using analytical methods or numerical methods such as Finite Element (FE). FE is one of the most powerful tools in the field of mechanistic modeling. It can be applied to model vast varieties of mechanical behaviors including linear elastic, nonlinear elastic, nonlinear elastoplastic such as Von-Mises, Mohr-Coulomb, hardening and continuous yielding ([3]; [4]; [5]).

In the second stage, the stresses and strains are determined under total or incremental application of wheel loads, to determine pavement distress such as rut depth or fatigue. Rutting and cracking will be estimated through empirical formulas under mechanical and environmental loads and cycles. Generally uniaxial quantities such as the tensile strain, at the bottom of the asphalt layer, vertical compressive strain, at the top of the subgrade layer, vertical stress, under the wheel load, and tensile stress, at the bottom of the asphalt layer, are used to calculate distresses using empirical formulas ([6]).

ME approach is an improvement compared to the purely empirical approach, noting that the Austroads method for empirical design is limited to granular pavements with thin $(<50 \mathrm{~mm})$ bituminous surfacing. However, it still includes empirical formulas which are potentially inaccurate predictions of distress due to simplifications made in the design process. These simplifications are often the result of a lack of available computer power.

In reality the pavement system has multidimensional geometry, anisotropy and nonhomogeneous nature. Pavement materials behavior is nonlinear and the response of the system is depended on multiple factors such as stress, strain, time, temperature and the repetitions of load. Therefore any improvement to the mechanistic stage of the design process will have a positive influence on the accuracy of design. A well-developed mechanistic method can consider all factors and determine the distress itself (not just stresses and strains) and hypothetically has the potential to predict the true behavior of pavement system.

\section{Review of Austroads and AASHTO Design Method}

The aim of pavement design is to select the most economical pavement thickness and composition which will provide a satisfactory level of service for anticipated traffic. To achieve the desired project reliability in the mechanistic design of flexible pavements it is necessary to use an appropriate performance relationship to estimate allowable loading from the calculated strains induced by a standard axle for each of three distress modes.

The purpose of structural analysis is to quantify the critical strains and/or stresses which are induced by the traffic loading in the trial pavement configuration. Here, it is usual to represent pavements as a series of layers of distinct property. The pavement layers may be considered to be fully elastic or viscoelastic, uniform in lateral extent, or variable, and with full friction, or no friction, between the layers. These variations have been used in an attempt to obtain theoretical estimates which agree with observed reactions to traffic loading. 
Subgrade.In the Austroads method the units of subgrade support are the California Bearing Ratio (CBR) and elastic parameters-vertical modulus (Ev), horizontal modulus (Eh) and Poisson's ratio (v). For thickness design purposes using mechanistic procedures, subgrade materials are assumed to be elastic and cross-anisotropic. A cross-anisotropic material is characterized by five parameters - two moduli (vertical, horizontal), and two Poisson's ratios (vertical and horizontal) and the additional stress parameter (f). The ratio of vertical to horizontal modulus is assumed to be 2 and both Poisson's ratios are assumed to be equal. The stress parameter $\mathrm{f}$ can be determined using the following relationship:

$$
\mathrm{f}=\frac{\text { vertical modulus }}{(1+\text { Poisson's ratio })} \text {. }
$$

The vertical modulus of subgrade can be determined from laboratory testing or by using the empirical relationship in which modulus in MPa is equal to 10 times CBR.

This relationship is, at best, an approximation and modulus has been found to vary in the range $5 \times$ CBR to $20 \times$ CBR ([7]). A maximum value of $150 \mathrm{MPa}$ is often adopted for subgrade materials, but this varies between road agencies. Representative values of Poisson's ratio for subgrades are 0.45 for cohesive materials and 0.35 for non-cohesive materials.

In AASHTO Guide for ME design, the required inputs are resilient modulus, Mr, Poisson's ratio, $\mu$ (elastic modulus for bedrock), a parameter used for quantifying stress dependent stiffness of unbound granular materials, subgrade materials and bedrock materials under moving loads. Resilient modulus is defined as the ratio of the repeated deviator axial stress to the recoverable axial strain. The inputs are used to characterize layer behavior when subject to stresses. Unbound materials display stress dependent properties.

Therefor AASHTO recommend using following equation to determine $\mathrm{M}_{\mathrm{r}}$ :

The vertical modulus of subgrade can be determined from laboratory testing or by using the empirical relationship in which modulus in MPa is equals to 10 times CBR.

This is, at best, an approximation and modulus has been found to vary in the range $5 \times$ CBR to $20 \times \mathrm{CBR}$ ([7]). A maximum value of $150 \mathrm{MPa}$ is often adopted for subgrade materials, but this varies between road agencies. Representative values of Poisson's ratio for subgrades are 0.45 for cohesive materials and 0.35 for non-cohesive materials.

In AASHTO Guide for ME design, the required inputs are resilient modulus, Mr, Poisson's ratio, $\mu$ (elastic modulus for bedrock), a parameter used for quantifying stress dependent stiffness of unbound granular materials, subgrade materials and bedrock materials under moving loads. Resilient modulus is defined as the ratio of the repeated deviator axial stress to the recoverable axial strain. The inputs are used to characterize layer behavior when subject to stresses. Unbound materials display stress dependent properties.

Therefor AASHTO recommend using following equation to determine $\mathrm{M}_{\mathrm{r}}$ :

$$
\mathrm{M}_{\mathrm{r}}=\mathrm{K}_{1}\left(\frac{\mathrm{I}_{1}}{\mathrm{P}_{0}}\right)^{\mathrm{k}_{\mathrm{z}}}\left(\frac{\tau_{\mathrm{oct}}}{\mathrm{P}_{0}}\right)^{\mathrm{k}_{\mathrm{g}}} .
$$

where

$$
\begin{aligned}
& \mathrm{I}_{1}=\sigma_{1}+\sigma_{2}+\sigma_{3} \\
& \tau_{\text {oct }}=\frac{1}{3} \sqrt{\left(\sigma_{1}-\sigma_{2}\right)^{2}+\left(\sigma_{2}-\sigma_{3}\right)^{2}+\left(\sigma_{3}-\sigma_{1}\right)^{2}}
\end{aligned}
$$


$\mathrm{P}_{0}=$ atmospheric stress

$\mathrm{K}_{1}, \mathrm{k}_{2}, \mathrm{k}_{3}$ : Are regression parameters

This is based on a model originally generated by [8].

Unbound Granular Materials. The most significant failure mode for Unbound Granular Materials (UGM) in mechanistic behavior of pavement layered system is permanent deformation or rutting.

Austroads indicates that stress dependency of vertical modulus can be modeled using the linear elastic model by dividing the granular layers into several sub layers, each assigned a vertical modulus to reflect the stress level at which it operates. However, the horizontal component of stress dependency cannot be directly modeled using a linear elastic model. The use of finite element models, which allow for stress dependent and anisotropic behavior in both the vertical and horizontal directions, would enable a more exact fit between calculated and measured deflections.

For pavement design purposes the appropriate value of the modulus of granular materials is the modulus obtained from laboratory repeated load triaxial testing at the material's in situ density, moisture content and stress levels under a Standard Axle.

There are two recommended methods for determining the modulus of the top granular sub layer, which in order of preference are:

1. direct measurement

2. assigning presumptive values

Modulus is influenced strongly by stress level, to an extent and nature dependent on material type. For unbound granular materials, modulus increases markedly with increasing mean normal stress and decreases with increasing shear stress, as shown typically by the same relationship which has been stated by [8] but for axisymmetric condition.

$\mathrm{E}=\mathrm{k}_{1} \times\left(\frac{\sigma_{\mathrm{m}}}{\sigma_{\mathrm{ref}}}\right)^{\mathrm{k}_{\mathrm{n}}} \times\left(\frac{\tau}{\sigma_{\mathrm{ref}}}+1\right)^{\mathrm{k}_{\mathrm{g}}}$

where in the repeated load triaxial test:

$\mathrm{E}=$ resilient modulus, $(\mathrm{MPa})$

$\sigma_{\mathrm{m}}=$ Mean normal stress, $\left(\sigma_{1}+2 \sigma_{3}\right) / 3,(\mathrm{KPa})$

$\tau=$ Octahedral shear stress, $\left.\sqrt{2(} \sigma_{1}-\sigma_{3}\right) / 3,(\mathrm{KPa})$

$\sigma_{\text {ref }}=$ Reference stress (atmospheric pressure $=100 \mathrm{KPa}$ )

$\mathrm{k}_{1}, \mathrm{k}_{2}, \mathrm{k}_{3}=$ Experimental parameters

This value will be inserted as input for CIRCLY program in mechanistic procedure as recommended by Austroad. However whilst being an input, the strain determinations are only used to predict strain in supported bound layers, and are not used to determine any failure mode within the granular material itself.

In AASHTO, models developed by Tseng and Lytton [9] were originally selected to estimate the permanent deformation of unbound granular and subgrade materials. Their relationship is:

$\delta_{\mathrm{a}}(\mathrm{N})=\beta_{1}\left(\frac{\varepsilon_{0}}{\varepsilon_{\mathrm{r}}}\right) \mathrm{e}^{-\left(\frac{P}{\mathrm{~N}}\right)^{\beta}} \varepsilon_{\mathrm{v}} \mathrm{h}$ 
$\beta$, $\varepsilon_{0}$ and $\rho=$ material properties

$\varepsilon_{\mathrm{r}}=$ Resilient strain

$\varepsilon_{v}=$ Average vertical resilient strain as obtained from the primary response model

$\mathrm{h}=$ Thickness of the layer

$\beta_{1}=$ Calibration factor

Asphalt. The most common modes of distress for asphalt layers on moderate-to-heavily trafficked pavements are:

- rutting and shoving due to insufficient resistance to permanent deformation

- Cracking due to fatigue

\section{Asphalt Fatigue}

Fatigue is one of the most recognized distress modes for asphalt failure. In the Austroads guide, it is indicated that when appropriate testing facilities are not available, asphalt fatigue characteristics will have to be adopted from those published in the literature.

For conventional bituminous binders used in asphalt placed on moderate-to-heavily trafficked pavements, the general relationship between the maximum tensile strain in asphalt produced by a specific load and the allowable number of repetitions of that load is:

$$
\mathrm{N}=\mathrm{RF}\left[\frac{6918\left(0.856 \mathrm{~V}_{\mathrm{b}}+1.08\right)}{\mathrm{S}_{\operatorname{mix}}^{0.36} \mu \epsilon}\right]^{5}
$$

where:

$\mathrm{N}=$ allowable number of repetitions of the load

$\mu \epsilon=$ tensile strain produced by the load (micro strain)

$\mathrm{V}_{\mathrm{b}}=$ percentage by volume of bitumen in the asphalt $(\%)$

$\mathrm{S}_{\mathrm{mix}}=$ asphalt modulus $(\mathrm{MPa})$

$\mathrm{RF}=$ reliability factor for asphalt fatigue

In AASHTO, The fatigue life of an asphalt concrete mixture is influenced by many factors. Several key mix properties such as asphalt type, bitumen content and air-voids are well known influences on fatigue performance. Other factors such as temperature, frequency, and rest periods of the applied load also are known to influence fatigue life. Other material properties may also affect the fatigue life such as PMB's, source of bitumen, aggregate/bitumen affinity etc. It is obvious that mix properties need to be carefully balanced to optimize fatigue cracking of any mixtures. In the literature, the most commonly used model form to predict the number of load repetitions to fatigue cracking is a function of the tensile strain and mix stiffness (modulus). The critical locations of the tensile strains may either be at the surface (resulting in top-down cracking) or at the bottom of the asphaltic layer (resulting in bottom-up cracking). The general mathematical form of the number of load repetitions used in the literature is shown in equation 5 (Austroads) and 6 (AASHTO). The form of the model is a function of the tensile strains at a given location and modulus of the asphalt layer.

$$
\mathrm{N}_{\mathrm{f}}=\left(0.0252 \mathrm{PI}-0.00126 \mathrm{PI}\left(\mathrm{V}_{b}\right)+0.00673 \mathrm{~V}_{b}-0.0167\right) \varepsilon_{t}{ }^{-5} S_{m}^{-1.4} .
$$

where: 


\section{PI $=$ Penetration Index}

\section{Permanent Deformation of Asphalt}

Austroads completely ignores the permanent deformation of asphalt layer in its design process. It indicates that while permanent deformation is well acknowledged as a distress mode of primary importance for asphalt, it is not included in the design procedures because no model is available which will reliably predict the development of rutting with the passage of traffic/time. It assumes that a properly designed mix will not rut within the design period.

In AASHTO it is stated that permanent deformation (rutting) of asphalt mixtures is one of the most important distress types in flexible pavement systems. Major research efforts are now underway to ensure that this important characteristic of asphalt materials is considered in both the mixture design stage and the structural design aspects of flexible pavement performance. The Design Guide provides the user with the capability to predict rutting within all asphalt and unbound layer materials. The constitutive relationship used in the 2002 Design GG-1.5 Guide is initially based upon the statistical analysis of laboratory repeated load permanent deformation tests. This model form is:

$$
\frac{\varepsilon_{p}}{\varepsilon_{r}}=a T^{b} N^{c}
$$

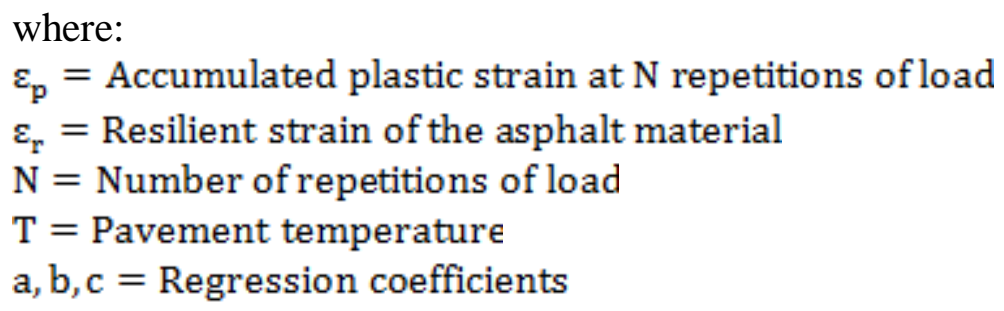

This equation is a simplification due to the limits of computer power in the time of development of the equation. With the current computer power available, the opportunity to refine the equation to more accurately model material performance exists.

Given a particular layered pavement cross section, the vertical resilient strain at any given depth (along a vertical axis, defined in the $\mathrm{x}$, y plane) is defined by knowledge of the three-dimensional stress state and the elastic properties (modulus and Poisson's ratio) of the AC layer in question from:

$$
\varepsilon_{\mathrm{rz}}=\frac{1}{\left|\mathrm{E}^{*}\right|}\left(\sigma_{\mathrm{z}}-\mu \sigma_{\mathrm{x}}-\mu \sigma_{\mathrm{y}}\right)
$$

The dynamic modulus ( $\left.\mathrm{E}^{*}\right)$ of an asphalt mix is employed in the Design Guide via a master curve. Thus, $\mathrm{E}^{*}$ is expressed as a function of the mix properties, temperature, and time of load.

\section{Summary of This Review}

As it can be observed from what has been reviewed so far, there are significant dissimilarities between AASHTO assumptions for mechanistic behavior of pavement materials and Austroads assumptions. A comparison of these two codes has been presented in Table 1. 
Table 1: Comparison between Austroad and AASHTO assumptions

\begin{tabular}{|c|c|c|}
\hline Pavement Layer & Austroad Assumptions & AASHTO Assumptions \\
\hline Subgrade & $\begin{array}{c}\text { elastic and } \\
\text { cross-anisotropic } \\
\text { modelled by five } \\
\text { parameters: } \\
\mathrm{E}_{\mathrm{v}}, \mathrm{E}_{\mathrm{h}}, \mathrm{v}_{\mathrm{v}}, \mathrm{v}_{\mathrm{h}}, \mathrm{f} \\
\end{array}$ & $\begin{array}{l}\text { Non-Linear stress } \\
\text { dependent elastic } \\
\text { modelled by two } \\
\text { parameters: } \\
\mathrm{M}_{\mathrm{r}}, \mu \\
\end{array}$ \\
\hline Subbase/Base (UGM) & $\begin{array}{l}\text { Non-Linear stress } \\
\text { dependent elastic } \\
\text { modelled by two } \\
\text { parameters: } \\
E_{\mathrm{r}}, \mathrm{v} \\
\end{array}$ & $\begin{array}{l}\text { Non-Linear elastoplastic } \\
\text { depended to number of } \\
\text { repetitions of traffic loads } \\
(\mathrm{N}) \text { and material } \\
\text { properties }\left(\beta, \varepsilon_{0} \text { and } \rho\right)\end{array}$ \\
\hline Asphalt layer (Rutting) & Ignored & $\begin{array}{l}\text { Viscoelastic behaviour of } \\
\text { asphalt depended to } \\
\text { temperature and number } \\
\text { of loading: } \\
\mathrm{E}^{*}, \mathrm{~T}, \mathrm{~N}\end{array}$ \\
\hline Asphalt layer (Fatigue) & $\begin{array}{c}\text { Elastic behaviour } \\
\text { modelled by two } \\
\text { parameters : } \\
\mathrm{V}_{\mathrm{b}}, \mathrm{S}_{\mathrm{mix}}\end{array}$ & $\begin{array}{c}\text { Elastic behaviour } \\
\text { modelled by one } \\
\text { parameter : } \\
\text { E }\end{array}$ \\
\hline
\end{tabular}

\section{Modelling of An Example Road}

A sample section of a layered pavement with same thickness, geometry and loading characteristics is modeled in the aforementioned programs. Figure 1 illustrates the geometry of the modeled pavement.

The material properties of the first model are listed in Table 1. All layers are assumed to behave linear elastically under a $0.75 \mathrm{MPa}$ pressure loading, which is applied over a circular area of $92 \mathrm{~mm}$ radius. This is taken as a circular representation of the tyre pressure in the AUSTROADS method employed in CIRCLY (AUSTROADS [10]).

Here traffic of a sample road in Western Australia (Kewdale Road South Bound north of Dowd) has been used to construct a model in two mechanistic design program namely CIRCLY and KENLAYER. The modeled pavement system has the same geometrical and mechanical properties in both programs. An analysis has been performed and the results of analysis in term of critical strains in each layer has been presented, compared and discussed.

Traffic Loading. The design lane would be the South Bound Kerb Lane. Table 2 and 3 represent the raw data and calculated traffic load for this sample road:

Table 2: South Bound Kerb Lane

\begin{tabular}{|c|c|c|c|c|c|c|c|c|c|c|c|c|c|c|}
\hline & \multirow{2}{*}{ हैं } & $\frac{n}{0}$ & $\ddot{n}$ & v & $\stackrel{n}{0}$ & $\frac{n}{0}$ & $\frac{n}{0}$ & $\ddot{v}$ & $\frac{n}{U}$ & $\frac{n}{U}$ & $\ddot{v}$ & $\frac{n}{0}$ & $\ddot{v}$ & $\frac{n}{v}$ \\
\hline & & - & $\mathrm{N}$ & $m$ & ナ & $n$ & 0 & r & $\infty$ & $a$ & 으 & $=$ & $\simeq$ & $\stackrel{m}{\sim}$ \\
\hline Weekdays & 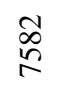 & हे & $\infty$ & ๙े & ర్ల్ల & f & i & ले & $\bar{\sigma}$ & $\sqrt[5]{5}$ & in & $\infty$ & 0 & $\approx$ \\
\hline Saturday & $\stackrel{\widehat{N}}{\infty}$ & $\overrightarrow{\mathcal{J}}$ & $n$ & $\stackrel{\Xi}{\Xi}$ & $\infty$ & $\underline{2}$ & $\nabla$ & \pm & $=$ & $R$ & $\tilde{ก}$ & ₹ & 0 & 0 \\
\hline
\end{tabular}




\begin{tabular}{|c|c|c|c|c|c|c|c|c|c|c|c|c|c|c|}
\hline \multirow{2}{*}{$\begin{array}{l}\text { Table } 2 \\
\text { Continue }\end{array}$} & \multirow{2}{*}{ 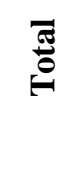 } & $\frac{n}{0}$ & $\frac{n}{0}$ & $\frac{n}{U}$ & $\frac{n}{0}$ & $\frac{n}{U}$ & $\frac{n}{0}$ & $\frac{n}{0}$ & $\frac{n}{0}$ & $\frac{n}{0}$ & $\frac{n}{U}$ & $\frac{n}{0}$ & $\frac{n}{0}$ & $\frac{n}{0}$ \\
\hline & & - & $a$ & m & + & in & 6 & r & $\infty$ & $a$ & ㅇ & $=$ & $\simeq$ & 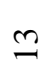 \\
\hline Sunday & $\stackrel{\infty}{\infty}$ & ลิ & $\stackrel{\infty}{\sim}$ & $m$ & ơ & r & - & $\infty$ & 0 & 8 & ले & in & - & - \\
\hline AADT & के & $\frac{a}{7}$ & $\stackrel{n}{i}$ & $\dot{a}$ & $\stackrel{4}{i}$ & $\ddot{m}$ & $\stackrel{n}{n}$ & $\bar{m}$ & $\vec{b}$ & $\vec{j}$ & $\dot{g}$ & $\stackrel{a}{\infty}$ & ?3. & สู่ \\
\hline Class \%age & & $\frac{1}{4}$ & I & $=$ & $\stackrel{n}{+}$ & 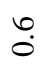 & $\stackrel{3}{0}$ & $n$ & $\stackrel{\infty}{\circ}$ & $\stackrel{\circ}{i}$ & $\infty_{\infty}^{\infty}$ & $\stackrel{?}{=}$ & $\stackrel{8}{\circ}$ & s. \\
\hline
\end{tabular}

Based on these data, traffic load has been calculated as many as $2.5 \times 10^{7}$ :

Table 3: Traffic calculation

\begin{tabular}{|c|l|l|l|l|l|l|}
\hline $\begin{array}{l}\text { Design period } \\
\text { (years) }\end{array}$ & AADT & CGF & HV\% & NHVAG & NDT & DESA \\
\hline 20 & 6080.7 & 24.3 & 26.1 & 2.5 & $3.52 \times 10^{7}$ & $2.5 \times 10^{7}$ \\
\hline
\end{tabular}

This traffic load has been applied to pavement layered system in both of the CIRCLY and KENLAYER programs. As recommended by Austroads, the tyre pressure for model has been set to $750 \mathrm{KPa}$. This load has been applied through a circular area of $92 \mathrm{~mm}$ radius and a single axle.

Geometrical and Mechanical Properties of Pavement Model. Figure 1 and Table 4 summarize the mechanical and geometrical assumptions which have been modeled in both programs:

Table 4: Mechanical and Geometrical Characteristics of the Model

\begin{tabular}{|c|c|c|c|}
\hline \multicolumn{4}{|c|}{ Resilient Moduli of Pavement Materials (MPa) } \\
\hline Subgrade & Subbase & base & Asphalt \\
\hline 50 & 100 & 200 & 3000 \\
\hline \multicolumn{4}{|c|}{ Poisson Ratio of Pavement Materials } \\
\hline Subgrade & Subbase & base & Asphalt \\
\hline 0.45 & 0.35 & 0.35 \\
\hline \multicolumn{4}{|c|}{ Thickness of Pavement Layers (Cm) } \\
\hline Subgrade & Subbase & base & Asphalt \\
\hline Infinite & 25 & 20 & 30 \\
\hline
\end{tabular}




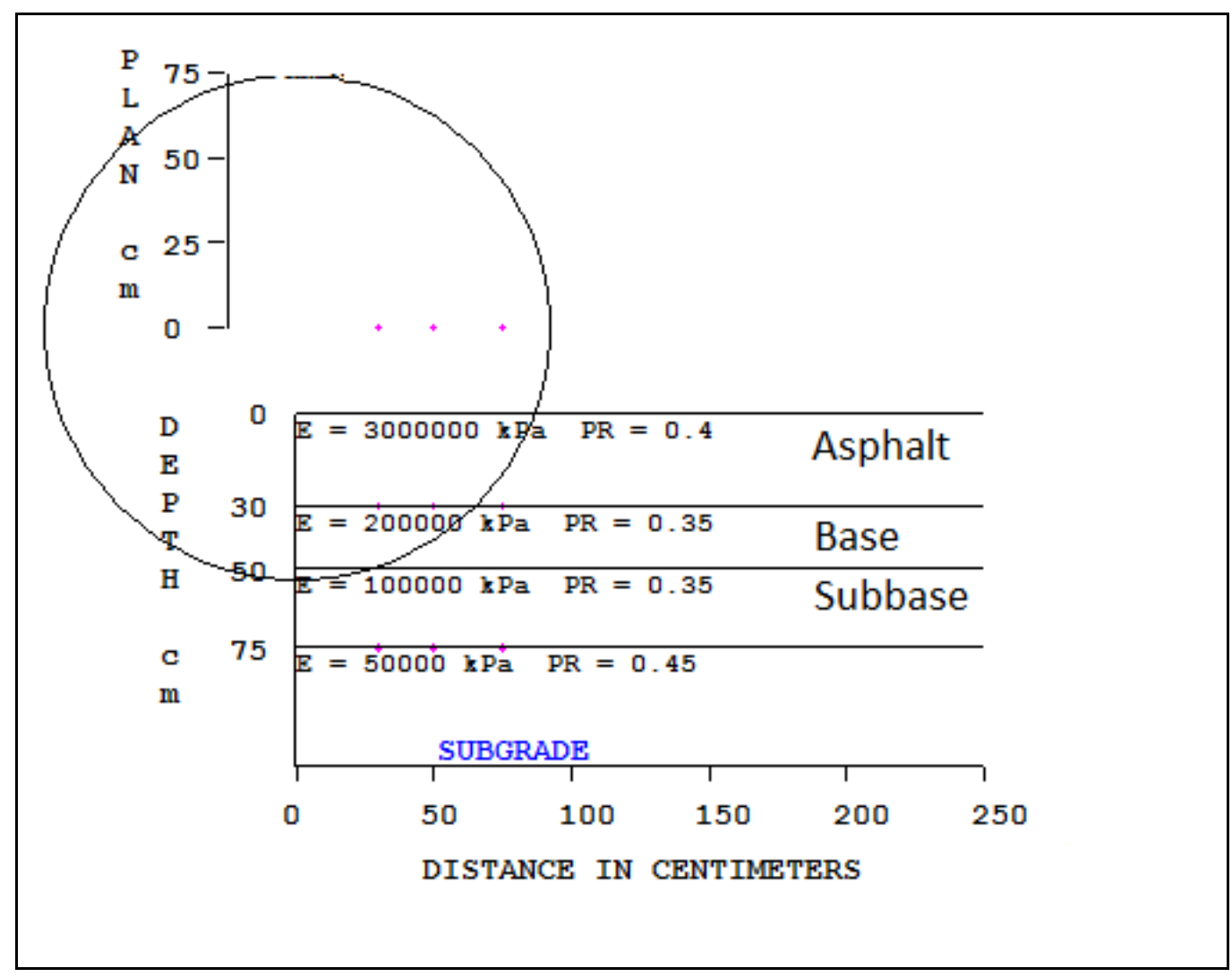

Figure 1: Layered Pavement System of the Model

Circly (5.0) and Kenlayer Assumptions and Methodology. CIRCLY (5.0) is the program used in Austroads mechanistic procedure. This software is widely used in Australia to design pavement layers. CIRCLY (5.0) is based on liner elastic method and performs analysis base on multilayer elastic behavior and assumes the subgrade behavior to be anisotropic.

The KENLAYER has been developed by Huang and is one of the most well-known software programs and underpins the AASHTO methodology. This computer program applies only to flexible pavements with no joints or rigid layers. The backbone of KENLAYER is the solution for an elastic multilayer system under a circular loaded area. The solutions are superimposed for multiple wheels, applied iteratively for nonlinear layers, and collocated at various times for viscoelastic layers. As a result, KENLAYER can be applied to layered systems under single, dual, dual-tandem, or dual-tridem wheels with each layer behaving differently, as linear elastic, nonlinear elastic, or viscoelastic. Damage analysis can be made by dividing each year into a maximum of 12 periods, each with a different set of material properties. Each period can have a maximum of 12 load groups, either single or multiple. The damage caused by fatigue cracking and permanent deformation in each period over all load groups is summed up to evaluate the design life.

Comparison of Model's Results between CIRCLY (5.0) and KENLAYER. Performing analysis, there is a significant difference between calculated strain from CIRCLY and KENLAYER. Table 5 represents the calculated strain from each program.

Consider the difference between transfer function.

It can be seen that calculated strains by CIRCLY is considerably larger than KENLAYER. For example, calculated critical strain for asphalt layer is 4.34 times larger than calculated tangential strain from KENLAYER.

The magnifying factor for calculated critical strain in subgrade relative to calculated vertical compressive strain in KENLAYER is 7.40. This difference comes from the assumptions of methodology for each program, the difference between the design procedure of AASHTO and Austroad and different transfer-functions used in each design method. 
Table 5: Calculated strain from CIRCLY and KENLAYER

\begin{tabular}{|c|c|c|c|c|}
\hline \multirow{2}{*}{$\begin{array}{c}\text { Location of strain } \\
\text { point }\end{array}$} & $\begin{array}{c}\text { CIRCLY } \\
(5.0)\end{array}$ & \multicolumn{3}{|c|}{ KENLAYER } \\
\cline { 2 - 5 } & $\begin{array}{c}\text { Critical } \\
\text { Strain }\end{array}$ & $\begin{array}{c}\text { Vertical } \\
\text { Strain }\end{array}$ & $\begin{array}{c}\text { Radial } \\
\text { Strain }\end{array}$ & $\begin{array}{c}\text { Tangential } \\
\text { Strain }\end{array}$ \\
\hline Asphalt & $-1.35 \mathrm{E}-04$ & $2.711 \mathrm{E}-05$ & $\begin{array}{c}-7.578 \mathrm{E}-0 \\
6\end{array}$ & $\begin{array}{c}-3.109 \mathrm{E}-0 \\
5\end{array}$ \\
\hline Subgrade & $2.73 \mathrm{E}-04$ & $3.690 \mathrm{E}-05$ & $\begin{array}{c}-6.426 \mathrm{E}-0 \\
6\end{array}$ & $\begin{array}{c}-2.349 \mathrm{E}-0 \\
5\end{array}$ \\
\hline
\end{tabular}

\section{Summary}

A detailed review has been undertaken on Austroads guide to pavement technology and AASHTO guide for mechanistic-empirical design. The main focus has been on the assumptions and methodology of each code regarding the mechanistic behavior of the pavement materials. A comparison has been presented in a table format to highlight the major differences. To demonstrate the effect of the assumptions a sample road has been modeled using the two program namely CIRCLY and KENLAYER. While CIRCLY assumptions are in accordance with Austroads guide, the KENLAYER performs analysis based on AASHTO methodology. The result of analysis has be presented and compared. A significant difference has been observed; CIRCLY determines a higher strain for a given load and is therefore, more conservative leading to a more costly pavement design in comparison to AASHTO.

\section{References}

[1]. Austroads, Guide to pavement technology. 2010. part2, pavement structural design

[2]. AASHTO, Guide for Mechanistic Empirical Design of New and Rehabilitated Pavement Structure. 2002.

[3]. Desai, C.S., Review of models and the disturbed state concept for thermomechanical analysis in electronic packaging. Journal of Electronic Packaging, 2001. 123: p. 19.

[4]. Schofield, A.N. and P. Wroth, Critical state soil mechanics1968, London: McGraw-Hill.

[5]. Vermeer, P., A five-constant model unifying well-established concepts1982: AA Balkema.

[6]. Huang, Y.H., Pavement analysis and design1993: Prentice-Hall Inc., New Jersey, USA.

[7]. Sparks, G.P., DW, An investigation into the relationship between California bearing ratio and modulus for two clays, 1982, Australian Road Research Board: Vermont South,Vic.

[8]. Witczak M. W., U.J., The universal airport pavement design system rep. I granular material characterization, 1988, Dept. of Civil Engineering, University of Maryland: College Park, MD, USA.

[9]. Tseng, K.H. and R.L. Lytton, Prediction of permanent deformation in flexible pavement materials. Implication of Aggregates in the Design, Construction, and Performance of Flexible Pavements, ASTM STP, 1989. 1016: p. 154-172.

[10]. AUSTROADS, Pavement Design - A Guide to the Structural Design of Road Pavements2004: Austroads, Sydney, Australia. 